\title{
A Measure of Perceived Identity Threat and of Distancing Relevant Others: Development of the Multiple Threat and Prejudice Questionnaire
}

\author{
Sára Bigazzi, Anna Siegler, Sára Serdült, Ildikó Bokrétás, Bálint Takács \\ Department of Social and Organizational Psychology, University of Pécs, Pécs, Hungary \\ Email: siegler.anna@pte.hu
}

How to cite this paper: Bigazzi, S., Siegler, A., Serdült, S., Bokrétás, I. and Takács, B. (2019) A Measure of Perceived Identity Threat and of Distancing Relevant Others: Development of the Multiple Threat and Prejudice Questionnaire. Open Journal of Social Sciences, 7, 237-254.

https://doi.org/10.4236/jss.2019.710019

Received: September 9, 2019

Accepted: October 19, 2019

Published: October 22, 2019

Copyright $\odot 2019$ by author(s) and Scientific Research Publishing Inc. This work is licensed under the Creative Commons Attribution International License (CC BY 4.0).

http://creativecommons.org/licenses/by/4.0/

\begin{abstract}
This paper reports the development of the Multiple Threat and Prejudice Questionnaire (MTPQ), a complex, multidimensional measure that assesses both identity threat on different dimensions of identification and the psychological distancing of outgroups relevant to each dimension. While mainstream approaches to prejudice focus on target groups and/or develop unidimensional measures, we present an instrument measuring the subjective perception of threat to different identity dimensions, which provides the condition to distance the other and to construct prejudice reinforcing and stabilizing self-boundaries. The present study confirmed the hypothetical factor structure based on data from 1482 participants.
\end{abstract}

\section{Keywords}

Prejudice, Psychological Distance, Self-Other Categorisations, Measurement

\section{Introduction}

The motivation behind scientific literature of prejudice is not only the scientific understanding of those phenomena related to it, but also how to contribute to reduce it [1]. Looking at prejudice as psychological distancing of perceived threat stimuli, intervention plans for its reduction need to take into account subjects psychological and identity states, more than the information biases concerning target groups. Prejudice is much more functional than we thought, and its reduction should be based on the psychological empowerment of the producers. To create these kinds of interventions we need an instrument that 
can capture identity-states related to relevant others.

At first we will present those theoretical considerations that fit to the acknowledgement of prejudice as a process of psychological distancing the Other, than without being exhaustive we present the existent measurements of prejudice and perceived threat, highlighting the demand of an instrument which is able to capture: oscillations of threat perceptions in different identity dimensions; the distancing of identity relevant Others; and the connectedness among them. Once embedded theoretically and presented a few alternatives, we present our two-scale instrument, the Multiple Threat and Prejudice Questionnaire (MTPQ). However the development of the instrument followed a longer process, the analysis will report the last validation with the data of 1482 Hungarian participants, confirming the hypothetical factor structure. At last we report a few critical considerations, propose further directions of investigation and present possible fields for usage.

\section{Prejudice as Context-Based Relevant Self-Other Categorisations}

Tajfel [2] draws attention to the ways individuals, through their group membership, perceive situations and society from their membership perspective, and think and behave accordingly. Prejudice and stereotypes are social as, when consensual, they arise from the constructed relations between the perceived social groups of a given context. They arouse from the shared perception of this contextual organization and individuals' adaptation to their social environment. As Tajfel highlights their social function, groups using stereotypes can ideologize collective actions, find causal explanations for large-scale social events to diminish anxiety, justify future and past actions against other groups, and reinforce differences between the ingroup and outgroup.

In the process of prejudice, the term social context not only refers to the social structure and the ongoing group conflicts but to all the social representational fields, a fabric of meanings through which communities and group members are able to communicate with each other. Constructivist approaches focus on the ways these contents and meanings structure psychological processes. With each act of representation, when we create and use knowledge, as well as prejudiced knowledge of who the others are, we also perform an act of identification: we define and recreate our perspective. To reduce anxiety and cope with the unknown, we "domesticate" the world around us [3] and by making sense of everyday life, we reconstruct differences between ourselves and others [4]. The social context paves the way for prejudice in the social arena, where the criteria for categorizations, the acknowledged groups to identify with as well as the contents associated with these groups are constructed by people and are objects of the symbolic struggle for power [5]. These meta-theoretical assumptions formed the theoretical basis for the development of an instrument measuring prejudice in its complexity.

Our basic assumption is that prejudice is a reaction to subjective perception of 
identity threat. Threat perception causes the psychological reinforcement of identity boundaries and consequently the distancing of the relevant other. The perception of threat, the strategies to deal with it, and the relevant others to distance are all offered by and strictly rooted in the normative system and social environment of the individuals. We developed a dynamic method to measure different identity threats and the distancing of relevant others on these identity dimensions.

Psychological processes such as categorizations and subsequently prejudice are strictly related to the contents through which they work. These contents are not only bits of information on a stimulus but emerge from and anchored in a very narrow way to the historical and social context in which we live. The social context and the power relations embedded in it define 1) the categories we are allowed to use in thinking 2) and the relevance of these categories. These categories define both other and self-representations, which in this way are inseparable from each other. In other words, identity and prejudice are the two sides of the same coin. Furthermore, the more significant a category is for us, the more we will distinguish it from other categories. The more important a quality is for us, the more extreme judgment we make of ourselves and of the others through this quality, with the aim of distinction [2]. According to Reicher, Haslam and Rakshi [6], acts of extreme inhumanity become possible when there is a constellation of the following conditions: ingroup identification, outgroup exclusion, outgroup threat and ingroup virtue. In our perspective, when people perceive others as threatening and think about self-other relations as repressive relations, where there is always a winner and a loser, psychological distancing and continuous social comparison become "useful" defense mechanisms.

Prejudice is a strong separation between the constructed self-image based on a relevant group membership and the others inherent in that membership. The more a group membership becomes important for the individual, the more the offered intergroup relations associated with that membership become relevant, and the more the ingroup-related representations, knowledge and possible actions will be activated, especially when facing unusual phenomena or situations.

From this perspective, prejudice is a defense mechanism, a reaction to subjectively experienced fear and threat to relevant identity dimensions. It provides a sense of security through creating psychological distance from the other, devaluating this other, and sometimes even depriving she/he of her/his human essence. The idea of deprivation of the other of her/his human essence is basic to theories and theoretical concepts such as dehumanization [2] [7] [8] [9], infrahumanization [10], and ontologization [11] [12] [13].

The instability arising from threat increases the need for reinforcing group boundaries, strongly framing and narrowing down the normal (ingroup) and the deviant (outgroup) categories (essentialism [14], 2011, naturalization [15]; or entitativity [16] [17]). The psychological instability caused by threat is inseparable from self-definition through differences, a permanent need to emphasize uniqueness and distinctiveness. According to Sociofunctional approach different groups 
elicit qualitatively different threats and thus qualitatively different emotional reactions, there is a "threat driven nature of intergroup affect" ([18], p. 771).

Outgroup exclusion is often conceptualized as a consequence of perceived outgroup threat, which arises from the narrow definition of the ingroup and the instability of the group identity [19]. Furthermore, threat can lead to changes in stereotypes [20] and to increased perceived homogeneity of the outgroup [21]. According to the Intergroup Threat Theory [22], high attachment to the ingroup, mistrust towards the outgroup, rigid social hierarchies, authoritarian norms, and negative intergroup relations in the past are all conditions that could predispose the perception of intergroup threat. Both the Sociofunctional approach and the Integrated Threat Theory create a causal relation between threat and prejudice, while the Justification-Supression Model [23] states that threat can be used to justify psychological and social distance from social groups. According to this model the expressed and experienced prejudice depends on those contextual elements that permit to justify or to suppress genuine prejudice. Thus perceived threat caused by prejudice but only if it is plausible and acceptable [24].

There is a debate on the relationships between perceived threat, negative feelings towards a group, and prejudice. Some authors suggest that these constructs do not differ sharply from each other [25] [26], while Shcheepers, Gijberts and Coenders [27] and Akrami, Ekehammar, Bergh, Dahlstrand and Malmsten [28] considers perceived threat and distancing as distinct processes. As Schaller, Park and Mueller states "all sorts of unnecessary antisocial acts-from bullying to gang violence to tribal warfare-are precipitated by threat and perceived vulnerability to danger" ([28], p. 1). According to our view, if we consider the self-other relationship as a unit of inquiry, there is no causal relationship between insecurity, threat and distancing the other. They are circular processes based in representations of hierarchical relationships, which reinforce each other in a circular way, when the social and normative frame allows it.

\section{Measuring Prejudice}

In most studies, prejudice is measured with paper-and-pencil tests focusing on negative/exclusive attitudes towards specific target groups. Social distance scale [29] was developed in 1924, and it is still widely used. Based on a similar approach, the Ethnic Group Rating [30] includes three items concerning general like and trust judgments regarding relevant outgroups, while the Thermometer Scales assess affective reactions to social groups [31].

Another frequently used self-report method enables the measurement of a distal constellation of attitudinal factors or ideological frame [32]. One of these more distal approaches focuses on the measurement of conventionalism, authoritarian aggression and authoritarian submission collectively referred to as Right-Wing Authoritarianism. The scale is based on an elaboration of the psychoanalytic theory and F scale developed by Adorno, Frenkel-Brunswick, Le- 
vinson and Stanford [33]. The 30-item instrument devised by Altemeyer [34] has been widely used, and a short version has also been developed [35]. Another distal approach to measure the ideological frame of prejudice is the Social Dominance Orientation Scale [36] based on the theory of social dominance. The 16-item version of the questionnaire distinguishes between those who prefer a hierarchically organized society based on status differences and those who believe in egalitarian communities. Both SDO and RWA proved positive predictors of prejudice and ethnocentrism.

Most questionnaires focus on one single dimension of prejudice, such as race, gender or age. A large number of questionnaires are still more concrete and specific to one target group of otherness. For instance, the Pro-Black/Anti-Black Attitude Questionnaire [37] and the Attitudes toward Roma Scale [38] assess attitudes towards one specific target group. The Fabroni Scale of Ageism [39] measures negative attitudes towards elderly people with 29 items composing three dimensions: antilocution, avoidance and discrimination. The Modern Sexism Scale [40] includes eight items which are worded in terms of denial of discrimination against women, opposition to women's request for impartial treatment and lack of support of anti-discrimination policies. The Ambivalent Sexism Inventory [41] differentiates between hostile and benevolent sexism. The former dimension is in line with the classic hostility-based conceptualization, whereas benevolent sexism can be defined as a set of attitudes that are seemingly positive and prosocial while actually being limited to stereotypical roles and gender hierarchy.

In line with the approaches proposed by Swim, Aikin, Hall \& Hunter [40], some researchers make a distinction between the two forms of prejudice (e.g., [42]: Classical and Modern Racial Prejudice Scale and Classical and Modern Sexism Scale; [43]: Old Fashioned and Modern Racism Scale; [44]: Blatant and Subtle Prejudice Scale). They operationalize the classical (blatant, old-fashioned, overt) form as direct, open and more hostile prejudice, whereas modern (covert or subtle) prejudice refuses overt discrimination while disapproves of the provision of special advantages (affirmative actions, positive discrimination) for target groups.

Maas, Castelli and Arcuri [45] propose an alternative approach to prejudice measurement focusing on more spontaneous forms of linguistic expressions such as respondents' descriptions of outgroup behavior, which reflect subtle linguistic biases stemming from prejudice. Other indirect measures such as the Implicit Association Test (IAT; [46]) are also available. The IAT is based on a forced categorization task requiring participants to rapidly categorize social stimuli under a positive or negative attribute.

\section{Measuring Threat}

Perceived threat is often measured explicitly with unidimensional scales [47], and not clearly distinguishing between threat and prejudice [48]. The Belief in a 
Dangerous World Scale by Altemeyer [49] consists 12 item, while Schlueter, Schmidt and Wagner [50] assessed perceived group threat with three items addressing both realistic and symbolic threat posed by "foreigners", similarly to Stephan and Stephan [19]. The authors point out that none of these items represents in itself derogation of the outgroup. McLaren [51] measured economic threat and cultural threat with five items focusing on "minorities". Scheepers, Gijsberts and Coenders [27] created a bi-factorial questionnaire which consists of 11 items and suggested that ethnic exclusionism and perceived ethnic threat are distinct phenomena. Sniderman, Hagendoorn and Prior [26] used a five-item test to differentiate between threat and aversion without focusing on specific target groups.

\section{Multiple Threat and Prejudice Questionnaire (Mptq)}

Our initial assumption was that prejudice assessment should focus on the dynamic aspects of identity stabilization and construction rather than on the representations of the outgroups. While identity threat could be investigated by its internal recognition or its external acknowledgement, the primary cue to prejudice is perception, thus internal recognition in our view. However, it has to be noted that threat perception is often incongruent with its normatively described conditions. The perception of threat and the threatening target arise together with the activated and often triggered abilities and strategies employed to deal with it. Socially shared and accepted coping strategies also consider the target as the object creating anxiety. One of the strategies to cope with threat is to create psychological distance from its object, preferably through devaluation if possible.

With these considerations in mind, we constructed two main scales. The Threat scale taps respondents' subjective feelings such as a sense of danger, threat and fear. The Distancing scale consists of items devaluating target groups. Both the Threat and the Distancing scale distinguish between different types of groups with different identity aspects and relevant others.

The first methodological step was to specify those relevant identity dimensions defined by everyday social discourses that are the most relevant by self-definition and prejudice construction. During the development in 2012, a first pilot study defined the focus of the measure after an item pool generation and investigated the factor structure and reliability of the test with 484 participants. A second pilot study included further exploratory scale and reliability analysis in a sample of 610 participants. The following section gives a detailed overview of the final dimensions, namely, the existential, national, gender and religion dimensions (Table 1).

We measured existential threat focusing mainly on material and economic well-being, a sense of security and personal control. Evidences shows that existential threat has consequences on intergroup prejudice [52] [53] [54]. We asked respondents about how much they felt their own and their families' economic 
existence was uncertain. We assumed that existential threat or a sense of relative deprivation could become over time a strong influencing factor behind any kind of prejudice. The relevant others distanced on the existential dimension could be either those in a higher economic position or those in a lower position. We tested distancing items in both directions of comparison.

The national dimension is based on the belongingness to the nation. Considering the nation as an imagined whole or unity [55] [56] [57], we assumed that the core of this entity comprising group members' beliefs about the nature of their communion not only influence the choice of the relevant other but also define its contents and intergroup behavior as well. The definition of citizenship determines who is excluded from and included in the group, and this categorization plays an important role in threat perception and distancing. We applied this specification in study 3 where we distinguished between different presumed cores of national unity and subsequently defined relevant others.

We also distinguished between different types of contents on which the perceived unity of the nation could be based, and we divided the related items into four subscales accordingly. Nations could be perceived as biological, cultural, social or economic unities. Those identifying with their national ingroup as a biological unity believe that group members share the same genetic or biological heritage, as the blatant prejudice based on genetical differences for Pettigrew and Marteens [44]. Traits, abilities and competencies are viewed as genetically coded entities. Target groups are viewed as threatening with genetic contamination by interbreeding or with a rapid growth in number because of their different reproductive strategies. This form of self-other distinction is the most dangerous because it could lead to the more and more aggressive expression of the desire to exterminate the threatening group, which may eventually be turned into action. The more individuals naturalize a group membership assumed to be given by birth, the more they psychologically close group boundaries.

Table 1. Multiple threat and prejudice questionnaire.

\begin{tabular}{|c|c|}
\hline Threat & Distancing \\
\hline \multicolumn{2}{|l|}{ Existential dimension } \\
\hline I think that impoverishment is a real danger for me. & If everyone worked as hard as I do, there would be no poverty. \\
\hline $\begin{array}{l}\text { I see it harder and harder to provide an adequate standard of living for } \\
\text { myself/ my family. (8) }\end{array}$ & $\begin{array}{l}\text { It is unfair that while state leaders enjoy welfare, many are starving. } \\
\text { (9) }\end{array}$ \\
\hline I often think about the possibility of losing everything I have. (7) & Rich people exploit others. \\
\hline I am assured that I will be able to provide for my children in the future. & Those having a lower standard of living should not have children. \\
\hline I think I cannot gain a clear understanding of the ways of society. & The unemployed are unemployed because they are too lazy to work. \\
\hline $\begin{array}{l}\text { I think it is my circumstances that determine my options when making } \\
\text { important decisions. (9) }\end{array}$ & Multinational companies have no regard for people's interests. (8) \\
\hline I think that the values I hold important do not prevail in the world. & $\begin{array}{l}\text { It is economic administration, banks and managers of multinational } \\
\text { companies that are responsible for the current situation. (10) }\end{array}$ \\
\hline I think I am not in control of my own life. & Politicians are corrupt. \\
\hline
\end{tabular}




\section{Continued}

Bio-National dimension

I think there is a real danger that white people become a minority in our homeland. (1)

The purity of our blood is put at risk by immigrants settling down in the country. (2)

It is important to me to avoid ethnic interbreeding. (2)

Aggressive behaviour and destructive tendencies are not hard-wired in immigrants (reversed item). (3)

I have no problem with a woman/man of my nation choosing a partner of a Children of minorities are born with poorer abilities than Hungarian different ethnic background (reversed item).

children. (1)

Cult-National dimension

I think that minorities prevent the people of my nation from being judged positively. (3)

Our values are better than those of other European countries.

Other cultures suppress our national traditions.

The culture of the minorities living with the nation is part of our culture. (reversed item)

I think that citizens of other countries appreciate our culture. (reversed item) Our culture is outstanding compared to that of other countries. (4)

Economic National dimension

The stability of our country is at risk because of a lack of adequate economic The cheap labour coming from abroad should not be admitted into growth. (5) the country. (6)

I am worried about the quality of the international representation of national economic interests. (4)

The levels of import should be reduced. (5)

I am not worried that domestic producers would be in a disadvantaged position as opposed to foreigners (reversed item).

It is beneficial for our economy that there are foreign companies operating in our country. (reversed item).

Socio-National dimension

The way equality before the law is applied in the jurisdiction makes me feel The national political elite is interested in undermining the cohesion anxious. (6) of the society.

It makes me feel worried that more and more people are deprived of access to education in the current system.

I am fed up with groups promoting views of social exclusion.

It makes me feel upset that in this nation we are unable to have respect for the differences between us.

It is the economic actors that are responsible for the increasing tensions in our society. (7)

Gender dimension

I would feel distressed if someone of my own gender would flirt with me. (13)

I would feel upset if I were considered being homosexual. (14)

As a woman, I would feel upset if it was not my duty to take care of the children in my family.

As a man, I would feel upset if it was not my duty to provide the necessary resources for my family. (15)

I think being the wage earner in the family does not suit a woman.

As a man, I think I cannot let myself appear weak.
I would feel distressed if I learned that a friend of mine was homosexual. (14)

I think that men and women have the same rights and obligations.

Women themselves are responsible for their failing to obtain leading positions.

Important decisions in a family have to be made by men. (16)

Women pursuing career ambitions are unattractive. (17)

It is not one's gender that determines one's responsibilities in the family.

I would still love my child if I learnt that they were homosexual. (15)

Religion dimension

I feel threatened by people of a religion different from mine.

The freedom of religion should be restricted. (11)

I am not free to think about religion as I like. (11)

It is important for all to follow the same religion. (12)

I think I am not free to choose what I believe in. (10)

A person of a religion different from mine could never make friends with me. (13)

I cannot freely disclose my views on religion to whomever I like. (12)
Different religious convictions can coexist in peace (reversed item). 
Perceived cultural homogeneity of a nation is based on shared values, traditions, language, history, lifestyles and worldviews, as the concept of subtle prejudice concern exaggerated cultural differences [44]. While this unity is perceived as being maintained by socialization and long-term shared existence, and thus it provides adequate stability, it also allows better permeability between psychological group boundaries and better chances of change. Target groups are threatening because they represent different cultural values and lifestyles.

Thinking about the nation as an economic unity is associated with different threats and target groups. The nation in this case is perceived as a community of shared economic interests whose members are interdependent in terms of material well-being. There is a competition with foreign corporations and workers that threaten the ingroups' economic system.

Finally, a nation could be perceived as an imagined community that defines the conditions of inclusion at a societal level including education, health care and all those issues that are of common interest to those living in a delimited space called a nation. In this case, target groups of prejudice could be considered those groups that hinder the development of the community.

Items addressing gender identity threat were based on traditional gender roles or sexual orientations. We assumed that traditional roles and heterosexual orientations would frame individuals with strictly limited and still dominant representations on how to behave according to their roles. Traditional representations of gender tend to biologize gender differences, and individuals sharing this kind of representations think about these differences as innate and genetically coded including both others and themselves. Any other kind of behavior, role or sexual orientation is viewed by these individuals as deviant and thus threatening. We think that those having a gender identity or sexual orientation outside the limits of traditional and dominant norms also feel threatened by anticipated social exclusion. However, we chose to measure threats associated with traditional representations of gender and sexuality because these are the threats underlying normative and socially dominant prejudice. Two different sets of items were designed to measure threats perceived by female and male respondents.

Threat to one's religious identity is posed by the anticipated restriction of one's freedom of religious credo to the advantage of other religious views. Prejudice or distancing the other on this identity dimension could be measured by assessing the implicit or explicit desire to restrict others' religious views. Items were constructed in the most general form possible, without embracing a specific religious credo. While the perceived threat concerns the religious credo in itself, distancing or prejudice is more closely related to religious affiliation and religious intergroup relations. In this respect, religion could be represented as a normative frame of a shared way of living, thus its diversity threatens the norms and values forming the basis of shared existence.

We constructed a two-scale measure focusing on the defense function of prejudice rather than on specific target groups. Feeling threatened as a mental state produces psychological distance between the self and the other. This shift to 
threat-based prejudice reduction strategies from those focusing on target group-relevant issues (e.g. unsuccessful cold integration processes based on the contact hypothesis, specific strategies based on insufficient or biased knowledge, information packages used in education concerning target groups) is based on the view that interventions aimed at prejudice reduction should fulfil an identity strengthening function. We also assume that attitudes towards target groups have a stronger normative frame than the expression of the associated inner, subjective mental states of fear and anxiety, therefore a measure tapping these mental states could better resonate with respondents' prejudicial views, and it could be more suitable for capturing small changes and thus for intervention assessment and evaluation. The instrument proposed in this paper was designed to meet these needs.

Tackling different identity dimensions together allows us to capture the complex representational fields rooted in a given social context, which is much more than a general prejudicial attitude of individuals. The organization of different identity dimensions, the value and importance attributed to them, the more or less close relationship between the different dimensions help us to develop more specific and targeted intervention programs.

\section{Study}

One of the first steps of developing the MTPQ was defining the focus of the measurement and then reviewing existing measures of related variables, brainstorming for new aspects and generating a large item pool. We preliminary examined the factor structure and psychometric properties of the questionnaire and the pilot study confirmed the hypothetical subscales. The psychological dimensions of the final questionnaire are reported below. The goal of the present study was to confirm the factor structure of the final questionnaire.

\subsection{Participants and Procedure}

The present data collection took place in 2017. Respondents were approached by the snowballing technique through social media groups and email messages with the help of pedagogy and psychology students of the University of Pécs. In order to reach out for a sample with a more variable socio-economic/educational background, students were asked not to spread the questionnaire among college students, but find diverse participants from their hometown above 18 years with different occupational background.

The overall sample included 1482 respondents $($ Mage $=37.1$, SDage $=15.086$, $60 \%$ female), all living in Hungary. Most participants lived in the capital (27.4\%) followed by county seats (25.4\%), other towns (26.9\%), and villages (20.3\%). Regarding education level, most participants completed college (42.2\%), university (40.2\%), high school education (15.9\%), phd (1.5\%) and less than eight grade

$(0.2 \%)$. To obtain a heterogeneous sample, the survey was made available in a paper-and-pencil format to different strata of the population. 


\subsection{Data Analysis}

Items were excluded from the questionnaire if they did not load above 0.4 on either factor, and they were selected on the basis of their contribution to psychologically meaningful factors that explained a significant proportion of the total variance. Confirmatory Factor Analyses were conducted to examine the structure of the questionnaire, while Cronbach's alpha coefficients were calculated to analyze internal consistency.

\subsection{Results}

A confirmatory factor analysis was conducted with the 61 -item final version of MTPQ based on the entire sample of 1482 respondents. The results of the two scales indicated an acceptable model fit: Identity threat scale: $\chi^{2}(80, \mathrm{~N}=1322)=$ 270.137, $\mathrm{p}<0.01, \mathrm{CMIN} / \mathrm{DF}=3.377, \mathrm{CFI}=0.971, \mathrm{TLI}=0.975, \mathrm{RMSEA}=0.04$ [90\% CI: $0.034-0.045]$, SRMR $=0.036$; Distancing scale: $\chi^{2}(108, \mathrm{~N}=1299)=$ 496.709, $\mathrm{p}<0.01, \mathrm{CMIN} / \mathrm{DF}=4.599, \mathrm{CFI}=0.931, \mathrm{TLI}=0.913, \mathrm{RMSEA}=0.049$ [ $90 \%$ CI: $0.045-0.054$ ], SRMR $=0.040$. The scales were reduced to 32 items according to item loadings in order to have a more practical final version. Loadings for identity threat ranged from 0.49 to 0.83 and for distancing from 0.44 to 0.75 . In our sample, the national threat factor was split into two subfactors. Biological and cultural items loaded in the same subfactor, while economic and societal items merged in another subfactor. We had the same results for the Distancing scale (Table 2).

Chronbach's alpha coefficients for the Identity threat factors ranged from 0.68 to 0.83 , while those for the Distancing scale ranged from 0.60 to 0.68 . The relatively low reliability values compared to the previous data collections are probably due to the reduced number of items on each scale, which served practicality. Previous studies show that lower Chronbach's alpha values are appropriate in case of short scales [58] [59].

Our aim was to develop a scale suitable for international comparisons and cultural changes over time. Thus the obtained factor dimensions and statistical results of internal consistency could be seen as dimensions perceived by participants. Tajfel [2] uses Lewin's distinction between genotypes and phenotypes to explain how results embedded in a specific context show us the phenotypes of phenomena, while we need to capture the genotypes of psychological phenomena. "The observed regularities of the behavior will result from the interaction between general processes and the social context in which they operate" ([2], p. 21). Thus we assume that internal consistency will be improved by international or intercultural sampling.

\subsection{Relationships between Identity Threat and Distancing}

Table 3 shows Pearson's correlations between the two scales of MTPQ. A significant positive relationship was self-evident between most of the relevant factors such as, for example, between Biological-cultural National Identity threat and 
Table 2. MTPQ subscales.

\begin{tabular}{cccccc}
\hline & $\mathrm{N}$ & $\alpha$ & $\begin{array}{c}\text { Factor } \\
\text { loadings }\end{array}$ & Mean & SD \\
\hline Bio-cultural National $^{\mathrm{a}}$ & 3 & 0.830 & $0.72-0.83$ & 3.768 & 1.860 \\
Socio-economic National $^{\mathrm{a}}$ & 3 & 0.695 & $0.57-0.72$ & 4.955 & 1.366 \\
Gender $^{\mathrm{a}}$ & 3 & 0.687 & $0.75-0.95$ & 5.142 & 1.640 \\
Existential $^{\mathrm{a}}$ & 3 & 0.719 & $0.55-0.80$ & 3.996 & 1.524 \\
Religion $^{\mathrm{a}}$ & 3 & 0.787 & $0.62-0.83$ & 2.034 & 1.344 \\
Bio-cultural National $^{\mathrm{b}}$ & 4 & 0.684 & $0.49-0.74$ & 3.522 & 1.461 \\
Socio-economic National $^{\mathrm{b}}$ & 3 & 0.602 & $0.44-0.72$ & 4.337 & 1.412 \\
Gender $^{\mathrm{b}}$ & 4 & 0.656 & $0.49-0.62$ & 1.892 & 1.195 \\
Existential $^{\mathrm{b}}$ & 3 & 0.673 & $0.54-0.73$ & 5.010 & 1.232 \\
Religion $^{\mathrm{b}}$ & 3 & 0.674 & $0.58-0.70$ & 2.307 & 1.280 \\
\hline
\end{tabular}

a. Identity threat b. Distancing.

Table 3. Correlations between identity threat and distancing factors.

\begin{tabular}{|c|c|c|c|c|c|}
\hline & $\begin{array}{l}\text { Bio-cult } \\
\text { National }_{\mathrm{a}}\end{array}$ & $\begin{array}{l}\text { Eco-soc } \\
\text { National }_{\mathrm{a}}\end{array}$ & Gender $_{\mathrm{a}}$ & Existential $_{\mathrm{a}}$ & Religion $_{\mathrm{a}}$ \\
\hline $\begin{array}{c}\text { Bio-cult } \\
\text { National }^{\mathrm{b}}\end{array}$ & $0.686^{* *}$ & $-0.055^{\star}$ & $0.403^{\star *}$ & $0.123^{\star *}$ & $0.280^{\star *}$ \\
\hline $\begin{array}{c}\text { Eco-soc } \\
\text { National }^{\mathrm{b}}\end{array}$ & $0.564^{* *}$ & $-0.096^{\star *}$ & $0.366^{* *}$ & $0.225^{\star *}$ & $0.204^{\star *}$ \\
\hline Gender $^{\mathrm{b}}$ & $0.308^{\star \star}$ & $-0.154^{\star \star}$ & $0.385^{\star \star}$ & 0.022 & $0.284^{\star *}$ \\
\hline Existential $_{\mathrm{b}}$ & $0.348^{\star *}$ & $0.245^{\star \star}$ & $0.211^{\star *}$ & $0.302^{\star *}$ & $0.075^{\star *}$ \\
\hline Religion $_{\mathrm{b}}$ & $0.318^{\star *}$ & $-0.108^{\star *}$ & $0.165^{\star *}$ & $0.062^{*}$ & $0.394^{\star *}$ \\
\hline
\end{tabular}

a. Identity threat b. Distancing. ${ }^{*} \mathrm{p}<0.05{ }^{* *} \mathrm{p}<0.01$.

Biological-cultural National Distancing $(r=0.686 ; \mathrm{p}<0.01)$, Gender Identity Threat and Gender Distancing $(r=0.385 ; \mathrm{p}<0.01)$, or Religious Identity threat and Religious Distancing $(r=0.394, p<0.01)$. However, some correlations seem to be specific to the Hungarian sample. While Socio-economic national identity threat had no significant correlations with the national distancing factors $\left(\mathrm{r}_{\text {bio-cult }}\right.$ $=-0.055 ; \mathrm{p}<0.05 ; \mathrm{r}_{\text {eco-soc }}=-0.096 ; \mathrm{n} . \mathrm{s}$.), Biological-cultural national identity threat showed correlations with both national distancing factors $\left(\mathrm{r}_{\text {bio-cult }}=\right.$ $\left.-0.689 ; \mathrm{p}<0.01 ; \mathrm{r}_{\text {eco-soc }}=0.564 ; \mathrm{p}<0.01\right)$. This clearly demonstrates the association between the two main scales and also suggests that these measures are not redundant.

Table 3 shows that in the Hungarian sample Biological-cultural National Identity Threat significantly correlated with each of the Distancing factors. This result can be interpreted as an outcome of the recent aggressive campaigns of the Hungarian government aimed at raising national identification and national feelings largely by framing certain social and political issues as threatening (such as the anti-Soros campaign, the anti-migration campaign or the national con- 
sultation through letters sent to each household, in which questions of an apparent public opinion poll implied large-scale threat), which in this specific cultural and ideological context reframed all other dimensions of identity: from how to be a real Hungarian man or woman, to what being religious means.

\section{Discussion}

The hypothetical threat and distancing aspects of the different identity dimensions of the MTPQ were confirmed by the analysis. The finalized version of the instrument consists of 32 items measuring both threat (15 items) and distancing the other (17 items). The final items are highlighted in italic for each dimension in the tables presented in the section Multiple Threat and Prejudice Questionnaire.

According to our results, material (existential) threat is related to national identity threat. Threat related to national identity based on a biological/cultural unity also defines religious and gender threat in the Hungarian context. It has been revealed that a general disposition to prejudice underlies distancing, while distancing at the level of biological nationhood seems to be the hub of the other distancing scales. This result is confirmed by the correlations between threat and distancing: bio-cultural nationhood threat covariates with each distancing scale, while eco-societal nationhood threat does not.

The presented study is based on a theoretical approach in which prejudice is considered as a result of perceived identity threat. Following this approach, a new questionnaire assessing perceived identity threat and psychological distancing was developed. The MTPQ and its subscales have good structural properties, moderate internal consistency. Although these findings are highly encouraging, additional construct validity assessment and international surveys are needed to corroborate the validity of each subscale. We believe that this questionnaire and the theoretical approach on which it is based provide adequate support for developing and evaluating balanced anti-prejudice programs in education. A key consideration when using the MTPQ is that a sense of threat produces psychological distance between the self and the other, therefore interventions aimed at prejudice reduction should rely on identity strengthening processes.

\section{Conclusion and Future Direction}

Considering prejudice as not an individual bias, but socially operating judgements and psychological distancing, highly functional for the identity of the sharing group members, our theoretical considerations motivated us to develop the Multiple Threat and Prejudice Questionnaire. The present study confirmed the hypothetical factor structure based on data from 1482 participants as well as highlighted the relation between different identity threat perceptions and the distancing of relevant others.

One of the limits of this instrument development is the specific cultural area 
within which it was conducted. With this study we tried to investigate the psychological properties of the Multiple Threat and Prejudice Questionnaire. However both the considered identity dimensions and the relevant outgroups are strictly rooted in the cultural context. Not only the importance of the different identity dimensions under consideration could change in other contexts or their relatedness, but also other dimensions could gain relevance, for example the economic or the age-related identification, as well as different relevant Others could become psychologically important. Our next step is an international data-collection with context adapted versions of the instrument. We consider it a worthwhile direction to explore the questionnaire in cross-cultural setup aiming to capture the genotype instead the phenotype of the phenomena of prejudice [2].

\section{Acknowledgements}

This research was funded by Grant No. K 119793 (The influence of social identity on intergroup prejudice and collective action) of the National Research, Development and Innovation Office (NKFIH). Preparation of this article was supported by the Hungarian National Excellence Program of the Ministry of Human Capacities [ÚNKP-18-4] and the János Bolyai Research Scholarship of the Hungarian Academy of Sciences granted to the first author.

\section{Conflicts of Interest}

The authors declare no conflicts of interest regarding the publication of this paper.

\section{References}

[1] Schaller, M., Park, J.H. and Faulkner, J. (2003) Prehistoric Dangers and Contemporary Prejudices. European Review of Social Psychology, 14, 105-137. https://doi.org/10.1080/10463280340000036

[2] Tajfel, H. (1981). Human Groups and Social Categories: Studies in Social Psychology. Cambridge University Press, New York.

[3] Moscovici, S. (1961/1976/2008) Psychoanalysis, Its Image and Its Public. Polity Press, Cambridge.

[4] Howarth, C. (2002) Identity in Whose Eyes? The Role of Representations in Identity Construction. Journal for the Theory of Social Behaviour, 32, 145-162. https://doi.org/10.1111/1468-5914.00181

[5] Jovchelovitch, S. (1996) In Defence of Representations. Journal for the Theory of Social Behavior, 26, 121-135. https://doi.org/10.1111/j.1468-5914.1996.tb00525.x

[6] Reicher, S., Haslam, S.A. and Rath, R. (2008) Making a Virtue of Evil: A Five-Step Social Identity Model of the Development of Collective Hate. Social and Personality Compass, 2, 1313-1344. https://doi.org/10.1111/j.1751-9004.2008.00113.x

[7] Kelman, H.C. (1973) Violence without Moral Restraint: Reflections on the Dehumanization of Victims and Victimizers. Journal of Social Issues, 29, 25-61. https://doi.org/10.1111/j.1540-4560.1973.tb00102.x

[8] Bandura, A. (2002) Social Cognitive Theory in Cultural Context. Applied Psychol- 
ogy, 51, 269-290. https://doi.org/10.1111/1464-0597.00092

[9] Haslam, N. (2006) Dehumanization: An Integrative Review. Personality and Social Psychology Review, 10, 252-264. https://doi.org/10.1207/s15327957pspr1003_4

[10] Gaunt, R., Leyens, J. and Demoulin, S. (2002) Intergroup Relations and the Attribution of Emotions: Control over memory for Secondary Emotions Associated with Ingroup or Outgroup. Journal of Experimental Social Psychology, 38, 508-514. https://doi.org/10.1016/S0022-1031(02)00014-8

[11] Moscovici, S. and Perez, J.A. (1997) Representations of Society and Prejudices. Papers on Social Representations Threads of Discussion.

[12] Chulvi, B. and Pérez, J.A. (2003) Ontologisation versus discrimination d'une minorité ethnique (les Gitans) Nouvelle. Revue de Psychologie Sociale, 2, 6-15.

[13] Marcu, A. and Chryssochoou, X. (2005) Exclusion of Ethnic Groups from the Realm of Humanity: Prejudice against the Gypsies in Britain and in Romania. Psicología Política, 30, 41-56.

[14] Toosi, N.R. and Ambady, N. (2011) Ratings of Essentialism for Eight Religious Identities. International Journal for the Psychology of Religion, 21, 17-29. https://doi.org/10.1080/10508619.2011.532441

[15] Holtz, P. and Wagner, W. (2012) Dehumanization, Infrahumanization, and Naturalization. In: Christie, D.J., Ed., Encyclopedia of Peace Psychology, Wiley-Blackwell, Malden, MA. https://doi.org/10.1002/9780470672532.wbepp079

[16] Campbell, D.T. (1958) Common Fate, Similarity, and Other Indices of the Status of Aggregates of Persons As Social Entities. Behavioral Science, 3, 14-25. https://doi.org/10.1002/bs.3830030103

[17] Yzerbit, V., Rogier, A. and Fiske, S.T. (1998) Group Entitativity and Social Attribution: On Translating Situational Constraints into Stereotypes. Personality and Social Psychology Bulletin, 24, 1089-1103. https://doi.org/10.1177/01461672982410006

[18] Cottrell, C.A. and Neuberg, S. (2005) Different Emotional Reactions to Different Groups: A Socio-Functional Threat-Based Approach to "Prejudice". Journal of Personality and Social Psychology, 88, 770-789.

https://doi.org/10.1037/0022-3514.88.5.770

[19] Stephan, W.G., Diaz-Loving, R. and Duran, A. (2000) Integrated Threat Theory and Intercultural Attitudes: Mexico and the United States. Journal of Cross-Cultural Psychology, 31, 240-249. https://doi.org/10.1177/0022022100031002006

[20] Quist, R.M. and Resendez, M.G. (2002) Social Dominance Threat: Examining Social Dominance Theory's Explanation of Prejudice as Legitimizing Myths. Basic and Applied Social Psychology, 24, 287-293. https://doi.org/10.1207/S15324834BASP2404_4

[21] Rothgerber, H. (1997) External Intergroup Threat as an Antecedent to Perceptions in in-Group and out-Group Homogeneity. Journal of Personality and Social Psychology, 73, 1206-1212. https://doi.org/10.1037/0022-3514.73.6.1206

[22] Stephan, W.G., Ybarra, O. and Morrison, K.R. (2009) Intergroup Threat Theory. In: Nelson, T.D., Ed., Handbook of Prejudice, Stereotyping, and Discrimination, Psychology Press, New York, 43-60.

[23] Crandall, C.S. and Eshleman, A. (2003) A Justification-Suppression Model of the Expression and Experience of Prejudice. Psychological Bulletin, 129, 414-446. https://doi.org/10.1037/0033-2909.129.3.414

[24] Bahns, A.J. (2017) Threat as Justification of Prejudice. Group Processes \& Intergroup Relations, 20, 52-74. https://doi.org/10.1177/1368430215591042 
[25] Bobo, L. and Hutchings, V. (1996) Perceptions of Racial Group Competition, Extending Blumer's Theory of Group Position to a Multiracial Context. American Sociological Review, 61, 951-972. https://doi.org/10.2307/2096302

[26] Sniderman, P., Hagedoorn, L. and Prior, M. (2004) Predisposing Factors and Situational Triggers: Exclusionary Reactions to Immigrant Minorities. American Political Science Review, 98, 35-49. https://doi.org/10.1017/S000305540400098X

[27] Scheepers, P., Gijsberts, M. and Coenders, M. (2002) Ethnic Exclusionism in European Countries: Public Opposition to Civil Rights for Legal Migrants as a Response to Perceived Ethnic Threat. European Sociological Review, 18, 17. https://doi.org/10.1093/esr/18.1.17

[28] Akrami, N., Ekehammar, B., Bergh, R., Dahlstrand, E. and Malmsten, S. (2009) Prejudice. The Person in the Situation. Journal of Research in Personality, 43, 890-897. https://doi.org/10.1016/j.jrp.2009.04.007

[29] Bogardus, E.S. (1925) Social Distance and Its Origins. Journal of Applied Sociology, 9, 216-226.

[30] Kiesner, J., Maass, A., Candinu, M. and Vallese, I. (2003) Risk Factors for Ethnic Prejudice during Early Adolescence. Social Development, 12, 288-308. https://doi.org/10.1111/1467-9507.00234

[31] Bobo, L. and Zubrinsky, C.L. (1996) Attitudes on Residential Integration: Perceived Status Differences, Mere in-Group Preference, or Racial Prejudice? Social Forces, 74, 883-909. https://doi.org/10.1093/sf/74.3.883

[32] Olson, M.A. (2009) Measures of Prejudice. In: Nelson, T.N., Ed., Handbook of Prejudice, Stereotyping and Discrimination, Psychology Press, Taylor \& Francis Group, New York, 367-381. https://doi.org/10.4324/9780203361993

[33] Adorno, T., Frenkel-Brunswik, E., Levinson, D. and Sanford, N. (1950) The Authoritarian Personality. Harper, New York.

[34] Altemeyer, B. (1998) The Other "Authoritarian" Personality. Advances in Experimental Social Psychology, 30, 47-91. https://doi.org/10.1027/1614-0001.27.3.117

[35] Rattazzi, A., Bobbio, A. and Canova, L. (2007) A Short Version of the Right-Wing Authoritarianism (RWA) Scale. Personality and Individual Differences, 43, 1223-1234. https://doi.org/10.1016/j.paid.2007.03.013

[36] Pratto, F., Sidanius, J., Stallworth, L.M. and Malle, B.F. (1994) Social Dominance Orientation: A Personality Variable Predicting Social and Political Attitudes. Journal of Personality and Social Psychology, 67, 741-763. https://doi.org/10.1037/0022-3514.67.4.741

[37] Katz, I. and Hass, R.G. (1988) Racial Ambivalence and American Value Conflict: Correlational and Priming Studies of Dual Cognitive Structures. Journal of Personality and Social Psychology, 55, 893-905. https://doi.org/10.1037/0022-3514.55.6.893

[38] Kende, A., Hadarics, M. and Lášticováb, B. (2017) Anti-Roma Attitudes as Expressions of Dominant Social Norms in Eastern Europe. International Journal of Intercultural Relations, 60, 12-27. https://doi.org/10.1016/j.ijintrel.2017.06.002

[39] Fraboni, M., Saltstone, R., Cooper, D. and Hughes, S. (1990) The Fraboni Scale of Ageism. Canadian Journal on Aging, 9, 56-66.

https://doi.org/10.1017/S0714980800016093

[40] Swim, J.K., Aikin, K.J., Hall, W.S. and Hunter, B.A. (1995) Sexism and Racism: Old-Fashioned and Modern Prejudices. Journal of Personality and Social Psychology, 68, 199-214. https://doi.org/10.1037/0022-3514.68.2.199 
[41] Glick, P. and Whitehead, J. (2010) Hostility toward Men and the Perceived Stability of Male Dominance. Social Psychology, 41, 177-185. https://doi.org/10.1027/1864-9335/a000025

[42] Akrami, N., Ekehammar, B. and Araya, T. (2000) Classical and Modern Racial Prejudice. A Study of Attitudes toward Immigrants in Sweden. European Journal of Social Psychology, 30, 521-532.

[43] McConahay, J.B., Hardee, B.B. and Batts, V. (1981) Has Racism Declined in America? It Depends on Who Is Asking and What Is Asked. Journal of Conflict Resolution, 25, 563-579. https://doi.org/10.1177/002200278102500401

[44] Pettigrew, T.F. and Meertens, R.W. (1995) Subtle and Blatant Prejudice in Western Europe. European Journal of Social Psychology, 25, 57-75. https://doi.org/10.1002/ejsp.2420250106

[45] Maass, A., Castelli, L. and Arcuri, L. (2000) Measuring Prejudice: Implicit versus Explicit Techniques. In: Capozza, D., Brown, R., Capozza, D. and Brown, R., Eds., Social Identity Processes. Trends in Theory and Research, Sage Publications Ltd., Thousand Oaks, CA, 96-116. https://doi.org/10.4135/9781446218617.n7

[46] Greenwald, A.G., McGhee, D. and Schwartz, J.L.K. (1998) Measuring Individual Differences in Implicit Cognition: The Implicit Association Task. Journal of Personality and Social Psychology, 74, 1469-1480. https://doi.org/10.1037/0022-3514.74.6.1464

[47] Matthews, M., Levin, S. and Sidanius, J. (2009) A Longitudinal Test of the Model of Political Conservatism as Motivated Social Cognition. Political Psychology, 30, 921-936.

[48] Makashvili, A., Vardanashvili, I. and Javakhishvili, N. (2018) Testing Intergroup Threat Theory: Realistic and Symbolic Threats, Religiosity and Gender as Predictors of Prejudice. Europe's Journal of Psychology, 14, 464-484. https://doi.org/10.5964/ejop.v14i2.1483

[49] Altemeyer, B. (1988) Enemies of Freedom: Understanding Right-Wing Authoritarianism. Jossey-Bass, San Francisco, CA.

[50] Schlueter, E., Schmidt, P. and Wagner, U. (2008) Disentangling the Causal Relations of Perceived Group Threat and Outgroup Derogation: Cross-National Evidence from German and Russian Panel Surveys. European Sociological Review, 24, 567-581. https://doi.org/10.1093/esr/jen029

[51] McLaren, L.M. (2003) Anti-Immigrant Prejudice in Europe: Contact, Threat Perception, and Preferences for the Exclusion of Migrants. Social Forces, 81, 909-936. https://doi.org/10.1353/sof.2003.0038

[52] Greenberg, J., Solomon, S. and Pyszczynski, T. (1997) Terror Management Theory of Self-Esteem and Cultural Worldviews: Empirical Assessments and Conceptual Refinements. In: Zanna, M.P., Ed., Advances in Experimental Social Psychology, Academic Press, San Diego, CA, 61-139. https://doi.org/10.1016/S0065-2601(08)60016-7

[53] Stephan, W.G., Ybarra, O., Martinez, C., Schwarzwald, J. and Tur-Kaspa, M. (1998) Prejudice toward Immigrants to Spain and Israel: An Integrated Threat Theory Analysis. Journal of Cross-Cultural Psychology, 29, 559-576. https://doi.org/10.1177/0022022198294004

[54] Schaller, M., Park, J.H. and Mueller, A. (2003) Fear of the Dark: Interactive Effects of Beliefs about Danger and Ambient Darkness on Ethnic Stereotypes. Personality and Social Psychology Bulletin, 29, 637-649.

https://doi.org/10.1177/0146167203029005008 
[55] Anderson, B. (1983) Imagined Communities. Reflections on the Origin and Spread of Nationalism. Verso, London.

[56] Gellner, E. (1983/2006) Nations and Nationalism. Blackwell Publishing, Oxford.

[57] Pehrson, S., Vignoles, V.L. and Brown, R. (2009) National Identification and Anti-Immigrant Prejudice: Individual and Contextual Effects of National Definitions. Social Psychology Quarterly, 72, 24-38. https://doi.org/10.1177/019027250907200104

[58] Tavakol, M. and Dennick, R. (2011) Making Sense of Cronbach's Alpha. International Journal of Medical Education, 2, 53-55. https://doi.org/10.5116/ijme.4dfb.8dfd

[59] Cortina, J. (1993) What Is Coefficient Alpha: An Examination of Theory and Applications. Journal of Applied Psychology, 78, 98-104. 